\title{
Ureteric Anastomotic Leakage
}

National Cancer Institute

\section{Source}

National Cancer Institute. Ureteric Anastomotic Leakage. NCI Thesaurus. Code C78662.

Leakage due to breakdown of a ureteral anastomosis. 